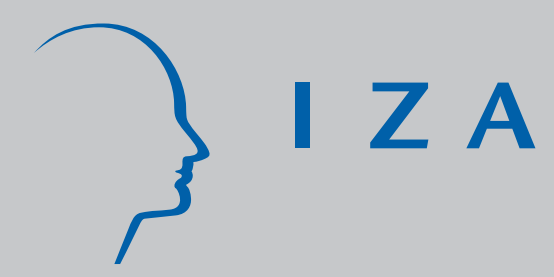

IZA DP No. 2174

U.S. Unemployment Duration:

Has Long Become Longer or Short Become Shorter?

J osé A. F. Machado

Pedro Portugal

J uliana Guimaraes

J une 2006 


\title{
U.S. Unemployment Duration: Has Long Become Longer or Short Become Shorter?
}

\author{
José A.F. Machado \\ Universidade NOVA de Lisboa \\ Pedro Portugal \\ Banco de Portugal, Universidade NOVA de Lisboa \\ and IZA Bonn \\ Juliana Guimaraes \\ Universidade Federal de Pernambuco
}

Discussion Paper No. 2174
June 2006

IZA
P.O. Box 7240
53072 Bonn
Germany

Phone: +49-228-3894-0

Fax: +49-228-3894-180

Email: iza@iza.org

\begin{abstract}
Any opinions expressed here are those of the author(s) and not those of the institute. Research disseminated by IZA may include views on policy, but the institute itself takes no institutional policy positions.

The Institute for the Study of Labor (IZA) in Bonn is a local and virtual international research center and a place of communication between science, politics and business. IZA is an independent nonprofit company supported by Deutsche Post World Net. The center is associated with the University of Bonn and offers a stimulating research environment through its research networks, research support, and visitors and doctoral programs. IZA engages in (i) original and internationally competitive research in all fields of labor economics, (ii) development of policy concepts, and (iii) dissemination of research results and concepts to the interested public.
\end{abstract}

IZA Discussion Papers often represent preliminary work and are circulated to encourage discussion. Citation of such a paper should account for its provisional character. A revised version may be available directly from the author. 


\section{ABSTRACT \\ U.S. Unemployment Duration: Has Long Become Longer or Short Become Shorter?*}

The U.S. labor market has been experiencing unprecedented high average unemployment duration. The shift in the unemployment duration distribution can be traced back to the early nineties. In this study, censored quantile regression methods are employed to analyze the changes in the US unemployment duration distribution. We explore the decomposition method proposed by Machado and Mata (2005) to disentangle the contribution of the changes generated by the covariate distribution and by the conditional distribution. The data used in this inquiry are taken from the nationally representative Displaced Worker Surveys of 1988 and 1998. We provide evidence that the change in the unemployment duration distribution is mainly produced by the opposing effects of a sharp rise in job-to-job transition rates and an increased sensitivity of unemployment duration to unemployment rates. Compositional changes in the labor force played a limited role. We rationalize our findings by arguing that improved screening technology is likely to be the relevant underlying mechanism at work.

JEL Classification: $\quad \mathrm{C} 14, \mathrm{C} 21, \mathrm{C} 41, \mathrm{~J} 64$

Keywords: quantile regression, duration analysis, unemployment duration, counterfactual decomposition

Corresponding author:

José A.F. Machado

Faculdade de Economia

Universidade NOVA de Lisboa

Campus de Campolide

1099-032 Lisboa

Portugal

Email: jafm@fe.unl.pt

\footnotetext{
* The authors thank John T. Addison, David Autor, and Olivier Blanchard for helpful comments and suggestions. They also gratefully acknowledge the partial financial support from the Fundação para a Ciência e a Tecnologia. The usual disclaimer applies.
} 


\section{Introduction}

The U.S. labor market has changed significantly over the last two decades. Unemployment rates fell below 4 percent and it has been argued that the "natural rate of unemployment" shifted downward to 5 percent or below. This sustained trend toward lower unemployment rates was largely driven by lower unemployment inflows. Concurrently, however, mean elapsed unemployment duration surprisingly trended up. Indeed, average unemployment duration reached an historical record high of 18 weeks in 2004. Figure 1 shows that the Current Population Survey (CPS) series of unemployment rates and median elapsed weeks of unemployment used to be very well-aligned until the end of the eighties. The two series began diverging significantly in the early nineties and the gap has widened ever since (see Figure 1).

The striking evolution of unemployment in the United States has not gone un-noticed. A number of studies have examined the question of why the unemployment duration became so much longer (Baumol and Wolf,1998; Valleta (1998); Abraham and Shimer, 2001; Juhn, Murphy, and Topel, 2002; and, Mukoyama and Sahin, 2004 ). Less explored has been the surprising fact that the rate of job changing without any intervening spell of unemployment also increased significantly during the nineties. Using data from the Displaced Worker Survey (DWS), Farber (2003) shows that the transition rates from joblessness into employment increased among displaced workers, most notably because the share of direct job-to-job transitions increased.

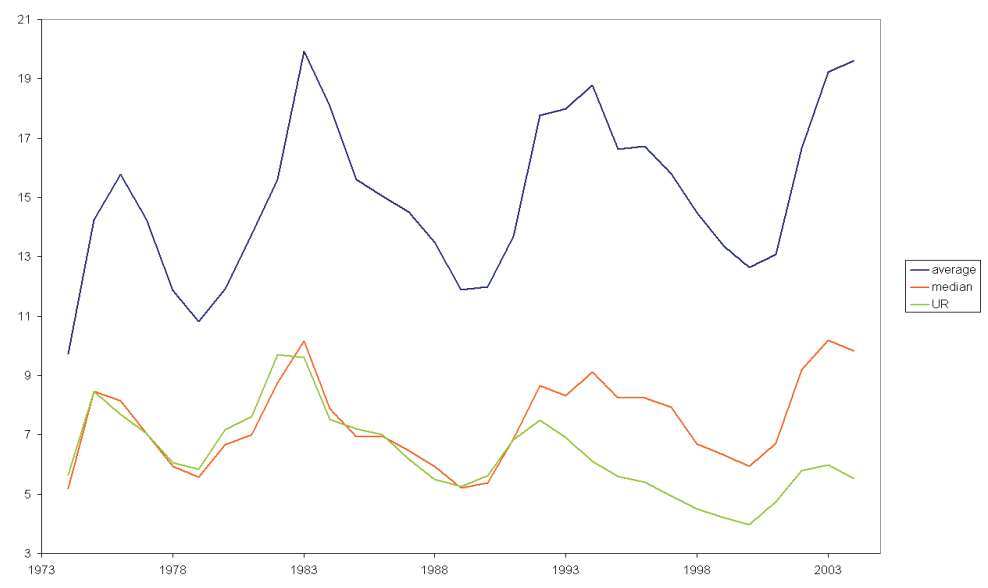

Figure 1: Unemployment RATE AND UnEMPloyment Duration 
Explanations for the recent rising trend of average unemployment duration rely either on the compositional changes of the labor force or, more fundamentally, on the emergence of some economic mechanisms. ${ }^{1}$ Examples of the former explanation include Abraham and Shimer (2001), who argue that the ageing of the baby-boom generation and the increased labor force attachment of women contributed to the observed enlarged share of long-term unemployed; Juhn, Murphy, and Topel (2002) who claim that joblessness among less-skilled men has taken the form of time spent out of the labor force rather than unemployment per se $;^{2}$ and Valleta (2001), who reports that the increase in average unemployment duration was produced by the joblessness experience of displaced workers.

Three main economic explanations have been offered for the observed lengthening of the average duration of unemployment. In the first uptake, Baumol and Wolf (1998) link average duration of unemployment to technical change, arguing that the acceleration of technical change has raised the share of the labor force that is unemployed in any period because plants close more often. Second, Mukoyama and Sahin (2004) note that increased within-group wage inequality, which translates into higher uncertainty about wage offer distribution, is likely to lead to longer periods of job search. Finally, Juhn, Murphy, and on Topel (2002) maintain that long-term changes in joblessness have been produced by adverse shifts in labor demand.

Improved search technology associated with, say, temporary-help agencies (Autor, 2001) or use of the Internet (Kuhn and Skuterud, 2004) do not appear, at first sight, to help explain longer spells of joblessness. However, we shall argue that more efficient search, coupled with improved sorting mechanisms (e.g., job screening), may indeed generate both longer average joblessness and higher job-to-job transition rates.

In this study, we rely on censored quantile regression methods to analyze the changes in the U.S. unemployment duration distribution. Quantiles seem appropriate to analyze unemployment duration for two main reasons. First, the methodology estimates the whole quantile process of duration time conditional on the attributes of interest, which constitutes a complete characterization of the distribution of duration time. Quantiles provide a natural way of characterizing

\footnotetext{
${ }^{1}$ The influence of methodological changes in the CPS surveys has also been studied (see, e.g., Abraham and Shimer (2001)).

${ }^{2}$ The relaxation of the Social Security Disability Insurance and Supplemental Security Income eligibility rules may also help to explain the increase in non-participation rates.
} 
important concepts such as short- or long-term unemployment, by focusing on the relevant tails of the duration distribution. Second, from a methodological standpoint, it is worth observing that quantile regression provides a unified and flexible framework for such an analysis.

Changes over time in the distribution of unemployment duration may be framed as resulting from changes in the distribution of the conditioning variables such as the age distribution or from changes in the conditional distribution of duration itself. We use Machado and Mata (2005) method to disentangle those effects. The basic building block is the estimation of the conditional distribution by quantile regressions; then, by resorting to resampling procedures, one estimates marginal distributions consistent with the estimated conditional model as well as with hypothesized distributions for the covariates. Comparing the marginal distributions implied by alternative distributions for the covariates one is then able to perform counterfactual exercises that isolate the different effects contributing to the overall change.

The data used in this inquiry are taken from the nationally representative Displaced Worker Surveys of 1988 and 1998. The DWS is a retrospective survey that has been conducted biennially since 1984 . In contains information on the nature of the job lost and the subsequent joblessness duration of workers displaced by reason of plant closure, slack work, or abolition of shift or position. The DWS is particularly well suited to study the distributional shape of unemployment duration because, unlike the CPS, it is a reprentative sample of the flow of displaced workers and because it provides information on completed spells of unemployment. ${ }^{3}$

The Machado and Mata decomposition reveals that the main force shaping the shift in the distribution of unemployment duration is the change in the regression coefficients. Here, two forces are at work. On the one hand, a higher incidence of job-to-job transitions in the nineties lead to a thicker left tail of the unemployment distribution, while on the other, longer durations for a given unemployment rate yielded a displacement of the unemployment distribution to the right. Short becomes shorter and long becomes longer. We subsequently offer a very simple model of a binomial mixture of duration distributions that is able to reproduce this outcome through the process of sorting generated by a more efficient screening technology. It is argued that whereas more-able individuals will face higher probabilities of being hired (and also of experiencing

\footnotetext{
${ }^{3}$ Is is demonstrably harder to characterize the distribution of an unemployed population based on the stock rather than the flow of the unemployed persons (Lancaster, 1990).
} 
direct job-to-job transitions), their less-able counterparts will confront a lower arrival rate of job offers, thereby lengthening their joblessness experience.

Under normal conditions, for the same unemployment rate, economists would trade higher inflows into unemployment for shorter mean unemployment durations. Risk aversion, distributional considerations, and the possibility of unemployment hysteresis (arriving from, say, human capital depreciation, stigmatization by employers, or loss of social networks) would justify that predisposition. We will argue, nevertheless, that longer (measured, i.e., excluding direct transitions) unemployment duration may simply be an inevitable outcome of a more efficient job screening process.

The paper is organized as follows. Section 2 describes the data set, providing a careful comparison of the two Displaced Worker Surveys used. Section 3 outlines the econometric methodology. The basic regression results are presented in Section 4. Section 5 deploys the Machado and Mata decomposition to sort out the forces behind the changes in unemployment duration. Section 6 concludes. ${ }^{4}$

\section{Data}

\subsection{General Description}

The data used in this inquiry are taken from the nationally representative, Displaced Worker Supplement to the February 1988 and 1998 Current Population Survey. The dataset - and changes in the survey, including the wording of the core displacement question and the recall period over which information on job loss is recorded - are well described elsewhere (see, for example, Kletzer, 1998; Farber, 2003), so that only brief introductory remarks are required here. The DWS has been conducted biennially since 1984. It contains information on the nature of the lost job and subsequent joblessness for workers displaced by reason of plant closure, slack work, or abolition of shift or position. Such data can be supplemented by extensive information on the personal characteristics of the worker contained in the parent CPS. The choice of the 1988 and 1998 surveys was guided by the need to use a comparable framework to the greatest extent. The 1988 DWS survey was the first to provide information for a single spell of joblessness (until 1986 the recorded jobless duration included multiple spells of joblessness). The 1998 survey is the most recent available survey with adequate data on joblessness duration. Still, there remain some issues of comparability

\footnotetext{
${ }^{4}$ The econometric details are presented in the Appendix.
} 
that will be discussed below.

The DWS has a number of advantages over administrative data. First, unlike the unemployment registry, the DWS survey covers both recipients and non-recipients of unemployment benefits. Second, because it is retrospective, the information on unemployment duration is not censored at the time of the exhaustion of benefits. And, third, the DWS allows the identification of transitions of displaced workers to another job without any intervening spell of unemployment.

It is important to collect information on job-to-job transitions because a non-negligible portion of the displaced worker does not observe a joblessness experience. More importantly, the incidence of this type of employment adjustment increased visibly from the 1988 survey to the 1998 survey. ${ }^{5}$

There are inevitably some shortcomings of the DWS data. Retrospective data are subject to recall bias - individuals experiencing displacement in past years may be more likely to understate their jobless duration than are more recent job losers - and respondents are prone to round (to months and quarters) their reported spells of unemployment. Beginning with the 1994 survey, however, the period over which job loss is measured has been reduced from five to three years, which should reduce the recall bias problem.

As mentioned above, since the 1988 survey the measure of unemployment has refered to the length of the single spell of joblessness that followed the displacement event and resulted in reemployment. To be sure, the definition still does not require the unemployed individual to be engaged in active search, so that this single spell may include intervals of suspended job search/withdrawal, but it no longer includes multiple spells of joblessness. A more recent innovation which affects the 1998 survey is that the DWS unemployment data are no longer top coded (at 99 weeks of joblessness). An additional source of right censoring in the data stems from our inclusion (via the CPS) of those individuals who failed to find work after displacement but who were nevertheless economically active as of the survey date.

Although we included those who wanted but never found employment after losing their jobs - as well as those individuals who transitioned directly into reemployment without any intervening spell of joblessness - we excluded indi-

\footnotetext{
${ }^{5}$ From an analytical point of view, one is interested, of course, in all the routes taken by the workers following the occurrence of a displacement event. The consideration of direct job-to-job transitions creates, however, some ambiguity in the measurement of unemployment duration. We shall discuss below the practical consequences of using different measures (including or excluding job-to-job transitions) of unemployment duration.
} 
viduals who were not economically active at the time of the survey. Further, because the nature of displacement is not well defined for certain individuals and sectors, those employed part time and in agriculture at the point of displacement were also excluded, as were those aged less than 20 years and above 61 years. These restrictions yielded a sample of 2,837 individuals for 1988 and 2,762 for 1998 .

\subsection{Comparability of the DWS Surveys}

There are a number of comparability issues that need to tackled. First, and most importantly, whereas the 1988 survey is a five-year retrospective data set of displaced workers based on the question "In the past five years, that is since January 1983, has ...lost or left a job because of a plant closing, an employer going out of business, a layoff from which...was not recalled, or other similar reason?", the 1998 survey is a three-year retrospective data set based on the question "During the last three calendar years, that is, from January of 1995 through December of 1997, did (name/you) lose a job, or leave one because a plant or company closed or moved, (your/his/her) position or shift was abolished, insufficient work, or another similar reason?". If the response to the job loss core question was positive, the respondent was asked whether the reason for displacement was 1) plant closing, 2) slack work, 3) position shifted or abolished, 4) seasonal job ended, 5) self-employment failed, and 6) other reasons. In line with the CPS definition of job displacement, only the first three situations will be considered in this study

Even though the slight change of wording is unlikely to raise any major comparison problems, the reduction of the retrospective period is potentially more serious. Since there is information on the year of displacement of the worker, one can minimize this problem excising from the 1988 sample the individuals displaced in 1983 and $1984 .{ }^{6}$ But this procedure does not completely solve the issue. If an individual experienced multiple spells of joblessness (which affects a fraction of displaced workers) the interviewer has instructions to record the episode where the worker lost the job with the longest duration. It may well occur that after loosing a long-tenure job during 1983 or 1984 an individual was displaced again during the 1985-1987 period. In this case, this displacement from a short-duration job is not registered. There is a clear implication for distortion of the distribution of job duration, with short job durations being likely

\footnotetext{
${ }^{6}$ Displacements that occurred during January of 1988 were also excluded. The 1998 survey does not include, by construction, workers displaced in 1998 .
} 
to be under represented in the 1988 survey in comparison with the 1988 survey. But there is no unambiguous implication for the distribution of unemployment duration. ${ }^{7}$

Second, even though unemployment rates were falling and labor market conditions were improving over the survey periods, the cyclical conditions were not identical. In fact, the average state unemployment rate at the time of displacement is 1.7 percentage points lower in the 1998 survey than the 1988 survey. We expect that by conditioning the unemployment duration distribution on labor market tightness, we will be able to isolate the impact of the business cycle.

Third, in both surveys the displaced workers are asked whether they received advance notice of impending their lay-off, but in the 1998 survey this question is restricted to written notice, where in the 1988 survey the individuals distinguish between informal and written notice. In order to make this variable as comparable as possible we will consider a notified only those workers who received written notice at least two months before the date of displacement.

Apart from these three comparability issues, which can be partially overcome, we are convinced that the two DWS surveys provide an adequate framework for characterizing the the evolution of the unemployment experience of displaced workers throughout the nineties.

\section{Composition and Structure}

The basic pieces of information to our counterfactual analysis are the changes in the attributes (covariates) of the jobless population and the changes in the distribution of duration for any given level of those attributes ("structure" or coefficient changes). The latter are estimated by censored quantile log-linear regressions (Koenker and Bassett, 1978 and Powell, 1984, 1986).

\subsection{Covariates}

Descriptive information on the two samples is provided in Table 2 and Figure 3. The composition of the 1998 sample differs from that of 1988 in some important

\footnotetext{
${ }^{7}$ Some checks can, however, be implemented. First, one can compare the job duration distribution for the 1983-1984 period with the 1985-1987 period. Second, one can exclude from both samples workers with fewer than two years of tenure in the pre-displacement job. And third, one can use our decomposition methodology to simulate the 1998 unemployment distribution with the 1998 job duration distribution. In all cases we arrive to the conclusion that the issue of multiple job spells does not significantly affect the comparison of the two unemployment duration distributions.
} 
ways.

\begin{tabular}{|r||c|c|}
\hline \multicolumn{1}{|c||}{} & \multicolumn{2}{c|}{ Sample Means } \\
\hline Age & $1985-1987$ & $1995-1997$ \\
\hline Gender (Male=1) & 0.650 & 38.3 \\
Race (White=1) & 0.869 & 0.562 \\
Marital status (Married=1) & 0.606 & 0.562 \\
Marital*Gender & 0.176 & 0.222 \\
Schooling & 11.6 & 13.2 \\
Tenure & 4.6 & 4.7 \\
Plant Closing & 0.480 & 0.395 \\
Written Notice & 0.054 & 0.131 \\
Unemp. Rate & 7.0 & 5.3 \\
Unemp. Duration (completed) & 12.7 & 11.2 \\
Job-to-job transitions & 0.120 & 0.189 \\
Proportion censored & 0.149 & 0.092 \\
Number of observations & 2837 & 2762 \\
\hline
\end{tabular}

Table 1: Sample Descriptive Statistics.

- The unemployment duration is visibly shorter in the 1995-97 period than during the 1985-87 period. This indication is best understood in the empirical survival functions (Kaplan-Meier estimates) exhibited in Figure 2., because unemployment duration is top-coded at 99 weeks for the 198587 period. Although this leftward shift is noticeable at both tails of the joblessness distribution, upper quantiles increased relative to the mean unemployment rate, as pointed out by Abraham and Shimer (2001). This indication is stronger if one considers the conventional measure of unemployment duration, where direct transitions without an intervening unemployment spell are excluded (see Table 2).

- The proportion of direct job-to-job transitions (joblessness spells with duration equal to 0 ) increased 7 percentage points

- Displaced workers in the nineties are older and better educated than during the eighties, reflecting the ageing of the baby-boom generation (see Figure 3).

- The proportion of female workers among displaced also increased sizeably, probably because labor market participation rates of women at risk of being displaced also increased over the relevant period. 


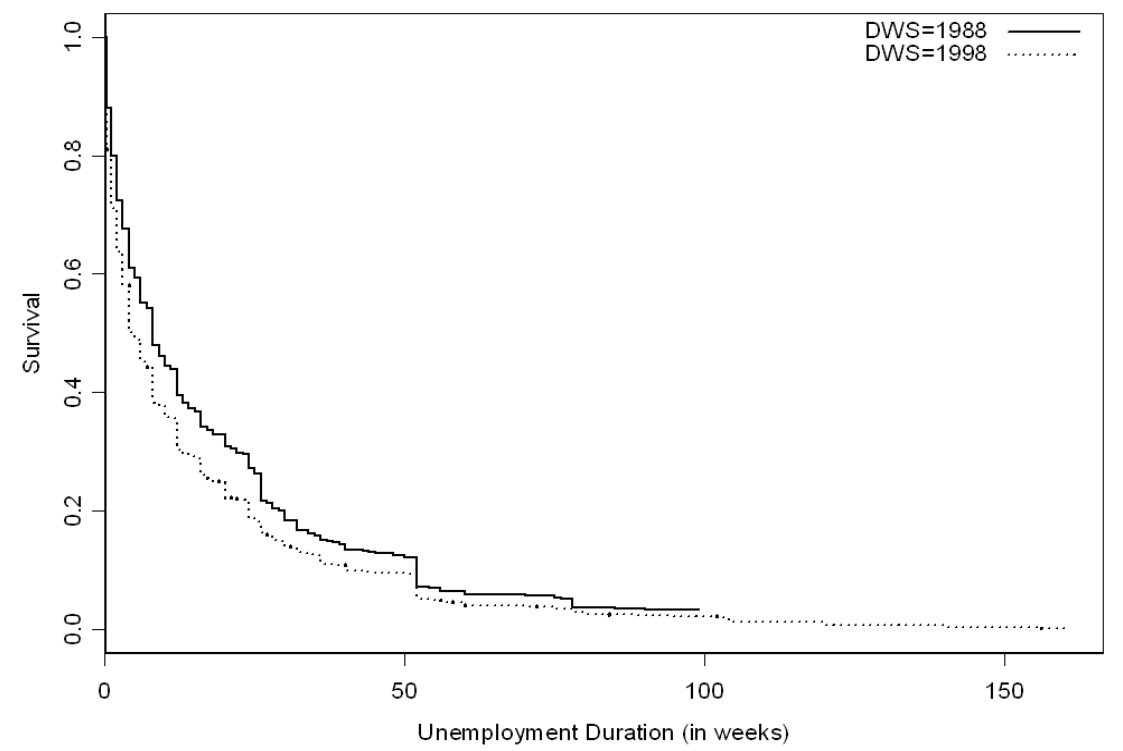

Figure 2: Kaplan-Meier Survival Functions.

- The likelihood of receiving formal notice of job lay-off more than doubled in the nineties, probably due to the introduction of the Worker Adjustment and Retraining Notification Act, which was enacted in 1988, which made pre-notification of displacements mandatory for mass-layoffs or shut-downs generated by large firms (Addison and Blackburn, 1994).

- Interestingly, despite the change in the reference period of job displacements (from five to three years), there are no significant changes in the distribution of job duration in the pre-displacement job (see Figure 3). It may still happen, however, that workers are now displaced with longer tenure than before.

\subsection{Coefficients}

We characterize the conditional distributions of jobless duration by quantile regression $(\mathrm{QR})$ models.

Empirical results for selected quantiles from fitting the QR model are given in Tables (3) and (4) for both surveys. For comparison purposes, we also pro- 

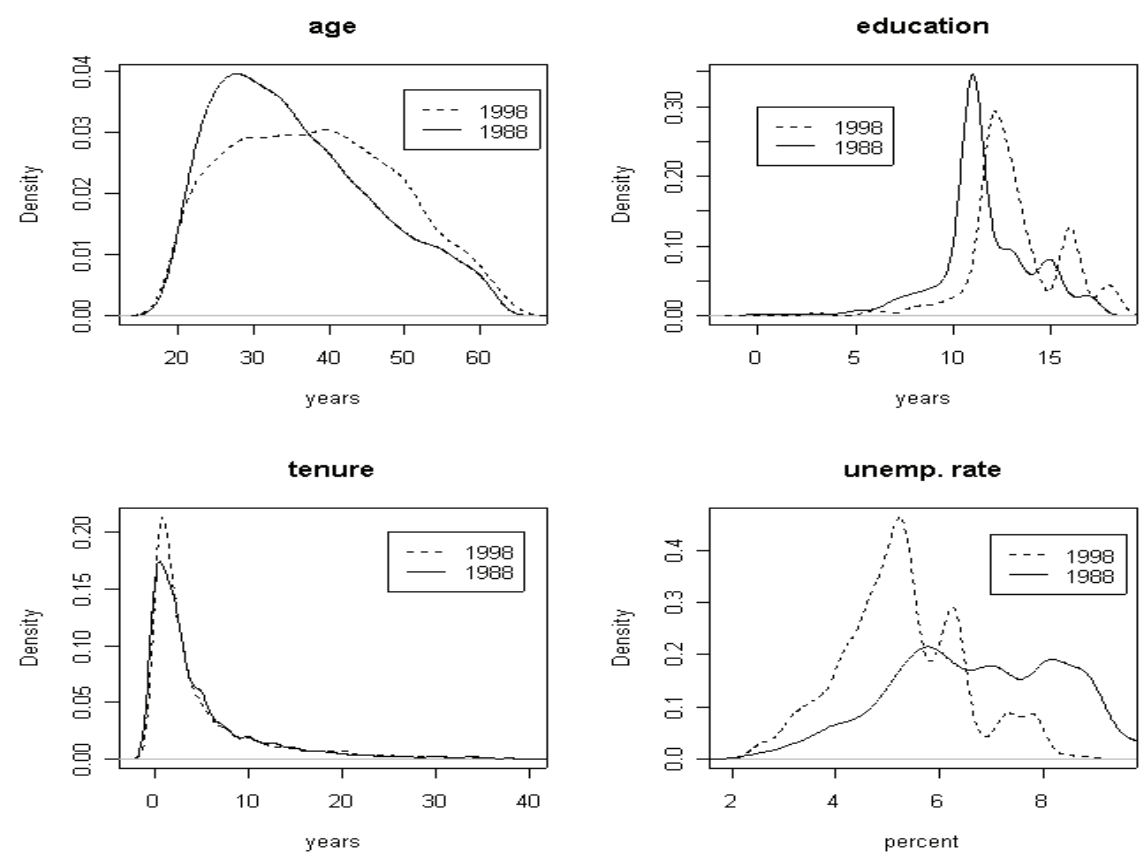

Figure 3: Kernel Densities for Age, Tenure, Schooling, and the UnEMPLOYMENT RATE. 


\begin{tabular}{|r||c|c|c|c|c|}
\hline \multicolumn{1}{|c||}{} & \multicolumn{5}{c|}{ Unemployment duration quantiles } \\
\hline & 0.10 & 0.25 & 0.50 & 0.75 & 0.90 \\
\hline \hline $1985-1987$ & & & & & \\
Including job-to-job transitions & 0.00 & 0.28 & 1.14 & 3.70 & 7.40 \\
Excluding job-to-job transitions & 0.28 & 0.57 & 1.56 & 3.70 & 7.40 \\
$1995-1997$ & & & & & \\
Including job-to-job transitions & 0.00 & 0.19 & 0.95 & 3.42 & 7.59 \\
Excluding job-to-job transitions & 0.19 & 0.57 & 1.52 & 4.55 & 9.87 \\
\hline
\end{tabular}

Table 2: Normalized Sample Quantiles of the Unemployment Duration Distribution. Quantiles are obtained from the Kaplan-Meier ESTIMATOR. VALUES ARE NORMALIZED By AVERAGE UNEMPLOYMENT RATES.

vide the estimates obtained from a Cox proportional hazard model and from an accelerated failure time (AFT) model that employs an extended generalized gamma distribution. ${ }^{8}$ Focusing on the 1985-1987 survey, the regression coefficient estimates are fairly conventional: ${ }^{9}$

- Age reduces escape rates proxying the reduced arrival rate of job offers with age.

- The impact of Tenure is statistically significant only at high quantiles. Its effect may capture the elevated reservation wages of long-serving workers.

- The result for race is familiar and captures the poorer opportunities facing non-whites as a result of both objective and discriminatory factors.

- The familiar (opposing) effects of marital status on reemployment probabilities - positive for males and negative for females - are also obtained. The result for married males presumably picks up a household head effect, and thus likely reflects the higher opportunity cost of unemployment for married males and their greater search intensity.

- Schooling enhances the chances of getting a job, but much more so for low durations. It can be argued that larger human capital endowments are associated with greater job opportunities and higher opportunity costs of unemployment that necessarily erode with the progression of the unemployment spell. A number of explanations can be suggested here: human

\footnotetext{
${ }^{8}$ See Addison and Portugal (1987) for an application of the extended generalized gamma distribution to unemployment duration.

${ }^{9}$ The continuous regressors were centered at their sample means. Consequently, the intercept estimates the quantile of the distribution of log duration for the "population" corresponding to these mean values and to the reference values of the binary regressors.
} 
capital depreciation, unobserved individual heterogeneity correlated with the measures of human capital, or employers' stigmatization of long-term unemployed, would lead to a fading human capital effect on the transition rate out of unemployment.

- Like schooling, written pre-notification (defined as written notice of at least two months) and job loss by reason of plant closure have significantly higher effects during the early phase of the unemployment spell. This pattern reflects the influence of on-the-job search. Faced with the prospect of an imminent discharge, the worker will engage in on-the-job search. If successful, he or she will experience a short spell of unemployment (Addison and Portugal, 1992).

- Identically, workers displaced by reason of plant closing - in comparison with workers dismissed due to slack work or position shifted or abolished - benefit from an essentially short-term advantage conveyed by job search assistance and early (and unmistakable) warning of displacement.

- As conventional, higher state unemployment rates are associated with longer spells of joblessness, mirroring, at the state level, lower arrival rates of job offers.

Despite broad agreement between the regression coefficient estimates from the two surveys, there are, neverthless, some differences. For their magnitude and potential impact on the unemployment duration distribution, two are most striking. First, the large increase in the sensitivity of duration to the unemployment rate, meaning that any given improvement in the macroeconomic conditions at the time of displacement translate into a much lower duration in 1998 than in 1988. Also the intercept dropped sharply and proportionately more so for low durations. This reflects the overall shift to the left of the distribution of duration largely generated, as we shall see, by the much higher incidence of direct transitions.

\section{Changes in the unemployment duration dis- tribution}

\subsection{An overall view}

The law of total probability implies that changes over time in the distribution of unemployment duration may result from changes in the distribution of the con- 


\begin{tabular}{|c|c|c|c|c|c|}
\hline & \multicolumn{3}{|c|}{ Quantile Regression } & \multirow[b]{2}{*}{$\mathrm{AFT}$} & \multirow[b]{2}{*}{ Cox } \\
\hline & 20 th & 50 th & 80 th & & \\
\hline Age & 0.012 & 0.024 & 0.016 & 0.021 & -0.014 \\
\hline (in years) & $(0.003)$ & $(0.003)$ & $(0.003)$ & $(0.004)$ & $(0.002)$ \\
\hline Gender & -0.013 & 0.354 & 0.224 & 0.328 & -0.224 \\
\hline$($ male $=1)$ & $(0.086)$ & $(0.086)$ & $(0.101)$ & $(0.099)$ & $(0.066)$ \\
\hline Race & -0.327 & -0.248 & -0.379 & -0.443 & 0.307 \\
\hline (white $=1$ ) & $(0.111)$ & $(0.111)$ & $(0.123)$ & $(0.096)$ & $(0.064)$ \\
\hline Marital Status & -0.422 & -0.330 & -0.210 & -0.327 & 0.209 \\
\hline$($ married $=1)$ & $(0.070)$ & $(0.076)$ & $(0.090)$ & $(0.083)$ & $(0.055)$ \\
\hline Married*Gender & 0.580 & 0.819 & 0.502 & 0.681 & -0.429 \\
\hline$($ married female $=1)$ & $(0.116)$ & $(0.119)$ & $(0.130)$ & $(0.131)$ & $(0.088)$ \\
\hline Schooling & -0.107 & -0.039 & -0.041 & -0.065 & 0.040 \\
\hline (in years) & $(0.014)$ & $(0.012)$ & $(0.013)$ & $(0.013)$ & $(0.009)$ \\
\hline Tenure & -0.006 & 0.009 & 0.024 & 0.011 & -0.008 \\
\hline (in years) & $(0.006)$ & $(0.006)$ & $(0.006)$ & $(0.006)$ & $(0.004)$ \\
\hline Plant Closing & -0.736 & -0.417 & -0.186 & -0.389 & 0.219 \\
\hline$($ Shutdown $=1)$ & $(0.062)$ & $(0.060)$ & $(0.064)$ & $(0.064)$ & $(0.041)$ \\
\hline \multirow[t]{2}{*}{ Written Notice } & -0.561 & 0.122 & 0.131 & 0.064 & -0.065 \\
\hline & $(0.163)$ & $(0.141)$ & $(0.171)$ & $(0.140)$ & $(0.093)$ \\
\hline \multirow[t]{2}{*}{ Unemp.Rate } & 0.089 & 0.124 & 0.115 & 0.106 & -0.071 \\
\hline & $(0.016)$ & $(0.015)$ & $(0.017)$ & $(0.016)$ & $(0.011)$ \\
\hline \multirow[t]{2}{*}{ Constant } & 1.240 & 2.290 & 3.552 & 2.039 & \\
\hline & $(0.131)$ & $(0.112)$ & $(0.120)$ & $(0.247)$ & \\
\hline \multirow[t]{2}{*}{ scale parameter } & & & & 1.536 & \\
\hline & & & & $(0.035)$ & \\
\hline \multirow[t]{2}{*}{ shape parameter } & & & & 0.639 & \\
\hline & & & & $(0.070)$ & \\
\hline
\end{tabular}

Table 3: UnEMPLOYMENT DURATION REGRESSION RESULTS FOR 1985-1887. 


\begin{tabular}{|c|c|c|c|c|c|}
\hline & \multicolumn{3}{|c|}{ Quantile Regression } & \multirow[b]{2}{*}{ AFT } & \multirow[b]{2}{*}{ Cox } \\
\hline & 20 th & 50 th & 80 th & & \\
\hline Age & 0.014 & 0.023 & 0.024 & 0.020 & -0.012 \\
\hline (in years) & $(0.004)$ & $(0.004)$ & $(0.004)$ & $(0.004)$ & $(0.002)$ \\
\hline Gender & 0.805 & 0.160 & 0.280 & 0.270 & -0.111 \\
\hline$($ male $=1)$ & $(0.107)$ & $(0.100)$ & $(0.093)$ & $(0.104)$ & $(0.061)$ \\
\hline Race & -0.851 & -0.360 & -0.287 & -0.435 & 0.225 \\
\hline$($ white $=1)$ & $(0.105)$ & $(0.108)$ & $(0.104)$ & $(0.102)$ & $(0.061)$ \\
\hline Marital Status & -0.906 & -0.391 & -0.397 & -0.435 & 0.210 \\
\hline$($ married $=1)$ & $(0.110)$ & $(0.097)$ & $(0.108)$ & $(0.097)$ & $(0.057)$ \\
\hline Married*Gender & 1.225 & 0.496 & 0.535 & 0.532 & -0.257 \\
\hline$($ married female $=1)$ & $(0.144)$ & $(0.146)$ & $(0.150)$ & $(0.139)$ & $(0.082)$ \\
\hline Schooling & -0.135 & -0.024 & -0.035 & -0.058 & 0.033 \\
\hline (in years) & $(0.018)$ & $(0.013)$ & $(0.015)$ & $(0.015)$ & $(0.009)$ \\
\hline Tenure & -0.024 & 0.022 & 0.030 & 0.016 & -0.013 \\
\hline (in years) & $(0.008)$ & $(0.006)$ & $(0.007)$ & $(0.006)$ & $(0.004)$ \\
\hline Plant Closing & 0.194 & -0.117 & -0.058 & -0.063 & 0.041 \\
\hline$($ Shutdown $=1)$ & $(0.080)$ & $(0.078)$ & $(0.079)$ & $(0.072)$ & $(0.042)$ \\
\hline \multirow[t]{2}{*}{ Written Notice } & -0.722 & -0.345 & -0.081 & -0.244 & 0.050 \\
\hline & $(0.217)$ & $(0.155)$ & $(0.159)$ & $(0.106)$ & $(0.061)$ \\
\hline \multirow[t]{2}{*}{ Unemp.Rate } & 0.249 & 0.184 & 0.170 & 0.183 & -0.107 \\
\hline & $(0.031)$ & $(0.026)$ & $(0.029)$ & $(0.029)$ & $(0.018)$ \\
\hline \multirow[t]{2}{*}{ Constant } & -0.067 & 2.040 & 3.189 & 1.102 & \\
\hline & $(0.124)$ & $(0.126)$ & $(0.122)$ & $(0.299)$ & \\
\hline \multirow[t]{2}{*}{ scale parameter } & & & & 1.743 & \\
\hline & & & & $(0.031)$ & \\
\hline \multirow[t]{2}{*}{ shape parameter } & & & & 0.317 & \\
\hline & & & & $(0.076)$ & \\
\hline
\end{tabular}

Table 4: UnEMPLOYMENT DURATION REGRESSION RESUltS FOR 1995-97. 
ditioning variables (e.g., labor force characteristics such as the age distribution) or from changes in the conditional distribution of duration itself (which may be thought of as changes in the way those labor force characteristics impact duration, the "coefficients"). The first is a composition effect and the second may be thought of as a "structural effect" (as in Author and Katz, 2005). Machado and Mata (2005) proposed a method (hereafter, M\&M decomposition) for disentangling those effects. The method is based on the estimation of marginal distribution of the variable of interest consistent with a conditional distribution estimated by quantile regression, as well as with any hypothesized distribution for the covariates. Comparing the marginal distributions implied by different distributions for the covariates one will then able to perform counterfactual exercises and identify the sources of the changes in the distribution of duration over the ten-year period (see Appendix A for further details).

Figure (4) presents such a decomposition in terms of changes in the hazard function. The "contribution of the covariates" results from comparing the hazard function that would have occurred in 1998 if all covariates had been distributed as in 1988 with the marginal hazard function estimated for 1998. The contribution of "coefficients" results from comparing the marginal hazard estimated with the 1988 data with the one that would have occurred in 1998 if all covariates had been distributed as in 1988 .

Several points are worth noting:

- Overall, there was a clear increase in the aggregate hazard rate for duration spells The increase in the hazard rate is more pronounced for the initial four weeks of unemployment. But this is simply an indication provided by the marginal hazard function, which, of course, combines into a single function both the changes in the covariates and the changes in the coefficients.

- Underlying the marginal hazard function, there is evidence that the changes in the covariates produced an increase in the hazard function lasting up to half a year.

- The "structural features of the economy" (that is, the changes in the coefficients), however, are responsible for the rise of the hazard function for short-term unemployed and a decline for longer-term unemployed. Indeed, hazard rates declined for durations longer than 5 weeks.

- Thus, after discounting the changes in the regressors over the ten-year 

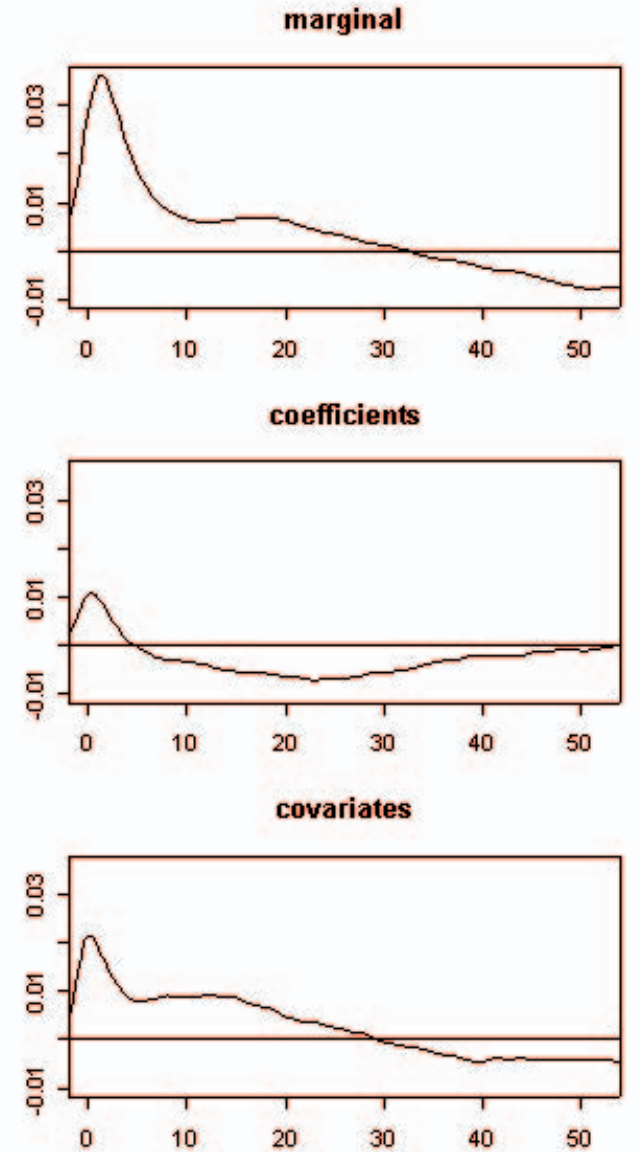

Figure 4: Decomposition of THE HAZARD FUnCTION CHANGES Top panel: estimated marginal for 1998 minus estimated marginal for 1988; Middle panel: contribution of the changes in the conditional hazard function; Bottom panel: contribution of the changes in the distribution of the covariates. 


\begin{tabular}{|r||c|c|c|}
\hline \multicolumn{1}{|c||}{} & \multicolumn{3}{c|}{ Quantiles (weeks) } \\
\hline \hline Marginal & 10 & 50 & 90 \\
\hline Cont. Cov's & -0.77 & -2.80 & -7.72 \\
Cont. Coef's & -0.41 & -1.82 & -11.17 \\
& & & $3.41^{\star}$ \\
\hline
\end{tabular}

Table 5: Contributions to CHANGes IN The QuAntiles of The UnEMPloYMENT DistRibUtion (WEEKS). MEdian of 500 REALizATions $\left((\cdot)^{\star} \sim\right.$ THE $97.5 \%-2.5 \%$ QUANTILE RANGE INCLUDES 0).

interval, short became shorter and long became longer

Table (5), which shows the contributions of changes in covariates and changes in the coefficients at different quantiles of the duration distribution, provides a less impressionistic view. "Covariate changes" appear to be more influential than "coefficient changes" reshaping the unemployment duration distribution. Whereas "covariate changes" led to shorter durations across the board, "coefficient changes" produced shorter durations at low quantiles and longer duration at high quantiles. The median unemployment duration decreased due to favorable contributions of both covariates and coefficients.

\subsection{Composition Effects}

As we have seen , the jobless population and the economic context of displacement change in the decade between surveys: becoming older and more educated; there is a higher proportion of females; written pre-notification of impending lay-off became more common; and the macroeconomic conditions at the time of displacement were more favorable. Overall, these changes decreased the jobless duration more or less uniformly for all durations. A finer analysis requires the estimation of the impact of each of those changes on the conditional distribution of durations.

Using the techniques described in Appendix A it is possible to isolate the contribution of the changes in the distribution of each covariate to the changes in the distribution of durations of joblessness spells. As it turns out, only three 


\begin{tabular}{|r||c|c|c|}
\hline \multicolumn{1}{|c||}{} & \multicolumn{3}{c|}{ Quantiles (weeks) } \\
& \multicolumn{3}{c|}{} \\
\hline & 10 & 50 & 90 \\
\hline \hline Age & -0.005 & 0.361 & 2.213 \\
& $-0.165 ; 0.177$ & $-0.780 ; 1.418$ & $-2.313 ; 7.296$ \\
\hline Gender (male=1) & -0.008 & 0.049 & -0.007 \\
& $-0.179 ; 0.170$ & $-0.998 ; 1.130$ & $-4.543 ; 5.180$ \\
\hline Unemp. Rate & -0.159 & -1.378 & -8.682 \\
& $-0.300 ;-0.019$ & $-2.348 ;-0.512$ & $-12.079 ;-4.911$ \\
\hline
\end{tabular}

Table 6: Contribution of Selected COVARIATes to The Change IN The QUANTILES OF THE UNEMPLOYMENT DISTRIBUTION. Median and 95\% interval estimates (in weeks) of the changes in the quantiles (1998 "minus" 1988) of the marginal and of the counterfactual distributions (based on 500 replications).

variables had a non-negligible composition effect (weighted by the estimated 1988 conditional distribution): age, gender and unemployment rate. Table (4.2) estimates the impact of these changes in three selected quantiles of the duration distribution. The figures represent the median and $95 \%$ interval estimates of the changes in the quantiles of the marginal and of the counterfactual distributions over 500 resamples. For instance, we estimate that the median duration is 1.39 weeks longer in 1988 than it would have been if the unemployment rate had been distributed as in 1998 (given the 1988 conditional distribution and keeping all other covariates with their 1988 sample distributions).

The ageing of the population increased durations mainly for the long-term unemployed (those in the right tail of the unemployment duration distribution). The larger share of women had a rather limited effect. The contribution of these two variables is, however, numerically small and estimated without much precision. Unemployment rate, on the other hand, caused a sizeable decrease of durations over the entire distribution, and appears to be the major force behind the composition effects.

\subsection{Changes in the conditional duration}

As we have already seen, the major changes in the conditional distribution were an increased sensitivity of duration to the unemployment rate and a steep downturn in the intercept (see Tables (3) and (4)). That is, unemployment 
duration increased relative to the unemployment rate (ceteris paribus) and the baseline subpopulation (of white married males, with average schooling and tenure, displaced without notice and by reasons other than plant closing in a state with average unemployment) experienced shorter unemployment spells. The former effect shifts the distribution of unemployment duration to the right while the latter shifts it to the left. This is a critical structural result, one that shapes the evolution of the unemployment duration distribution, even though is partially counteracted by the change in the intercept.

Figure (5) represents the ceteris paribus magnitude of those shifts in weeks.Per $s e$, the drop in the intercept is estimated to reduce the median duration by 2.30 weeks. On the other hand, the higher sensitivity to the unemployment rate increases the median duration by 4.90 weeks. The joint effect of the two coefficient shifts tuns out to be 0.83 weeks at the median. It should be noted, nevertheless, that the change in the unemployment rate coefficient is particularly strong at the right tail of the unemployment duration distribution. Because of this, the net effect of the two coefficient changes produces a sharp increase in unemployment duration at the upper quantiles of the distribution (see the third panel of Figure (5)), making long durations longer.

\subsection{Summary}

We have identified three major forces reshaping the unemployment duration distribution. One is the improved overall economic environment as measured by the lower state unemployment rate at the time of displacement. Interestingly, composition effects related to age and gender appear to have played no significant role.

The other two forces, with conflicting impacts on the duration distribution, relate to more fundamental economic mechanisms were: the sharp decline in the intercept and the higher sensitivity of unemployment duration to unemployment rates. In the next sections we will show how these changes are related to the upward trend of job-to-job transitions in the U.S. labor market as indicated by Farber (2003), and may be explained by improved job screening processes.

\section{Job-to-job transitions}

Job-to-job transitions increased sharply from the 1988 to the 1998 survey. In fact, the proportion of direct transitions increased from 12 percent to 18.9 per- 

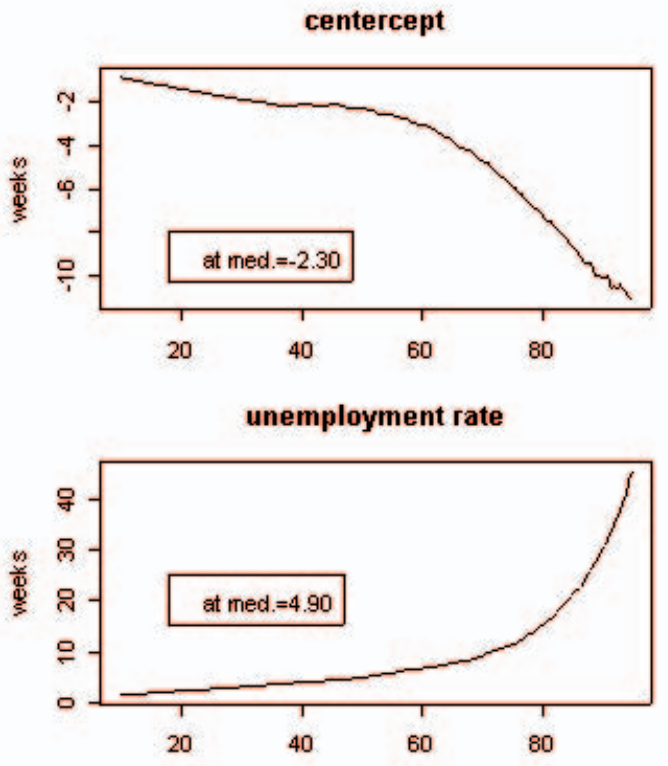

joint effect

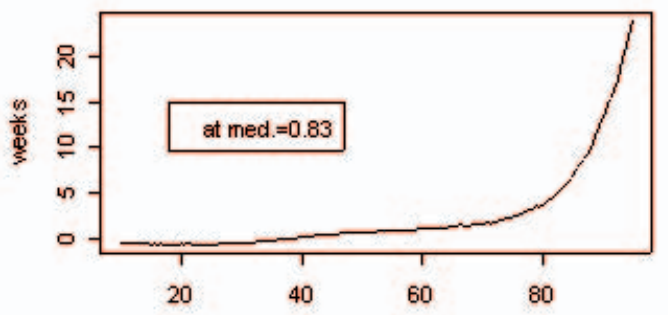

Figure 5: IMPACT ON DURATION (IN WEEKS) OF CHANGES IN QR COEFFICIENTS. 


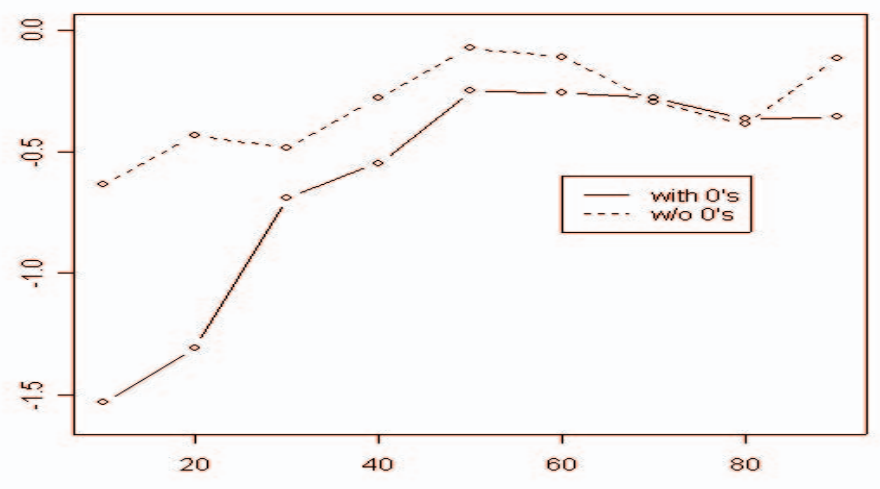

Figure 6: InCREASED JOB-TO-JOB TRANSITIONS AND CENTERCEPT CHANGES.

cent over this period. A hike in the share of job-to-job transitions is expected because labor market conditions improved, as indicated by the decline of the unemployment rate, but the increase in job-to-job transitions was over and above what was to be expected from the lower unemployment rates. ${ }^{10}$ Furthermore, it appears that the incidence of job-to-job transitions became more sensitive to the UR. It is clear that job-to-job transitions played a pivotal role in the U.S. labor market over this period. Job-to-job flows are often neglected in the analysis of labor market adjustments, but there is an increasingly widespread belief that such flows play a center-stage role (Fallick and Fleischman, 2004; Hall, 2005; and Shimer 2005). ${ }^{11}$

The evidence on job-to-job transitions naturally leads to the following two questions: Is the drop in the intercept accounted for by an increased share of direct transitions? Is there a connection between the increased sensitivity to the unemployment rate and the share of direct transitions? A straightforward way to answer these questions is to exclude employment changes without an intervening joblessness spell in the estimation procedure. It is clear that in proceeding in this way one uses a more conventional definition of unemployment duration, though at the cost of some (important) informational loss.

The quantile regression estimate for the intercept in a sample restricted

\footnotetext{
${ }^{10} \mathrm{~A}$ straightforward probit regression of the probability of direct transitions on the unemployment rate and a dummy variable identifying the 1998 survey gives a positive and statistically significant regression coefficient to the survey dummy.

${ }^{11}$ See Blanchard and Diamond (1990) for an early treatment of worker flows in the U.S. labor market.
} 
to durations greater or equal to one week is summarized in Figure (6). It is transparent in the figure that the drop in the intercept at the left tail of the distribution that is observed in the 1998 survey reflects in large part the increase in the incidence of job-to-job transitions. This outcome very likely reflects the increase in the probability mass at very low durations. ${ }^{12}$

\section{A simple accounting framework}

How to reconcile higher exit rates at low duration with higher average duration or longer right tails of the duration distribution? Here, a tentative explanation based on the notion of improved search technology will be offered. Our reasoning is based on the evidence of the widespread reliance of firms on temporary help agencies (Autor, 2001), on the increasing popularity of internet job search and hiring (Kuhn and Skuterud, 2004), the introduction of profiling procedures by the state unemployment insurance offices (Katz and Krueger, 1999; Berger, et al., 2001 ), and the extensive use of (low-cost) job screening tests and flexible staffing arrangements (Houseman, 2001 and Autor and Scarborough, 2004). In essence, it will be argued that improved job screening mechanisms may indeed lend support to the twofold outcome of longer average (measured) unemployment duration and higher job-to-job transition rates.

We subsequently, explore a very simple model of a binomial mixture of duration distributions that is able to reproduce this outcome through the process of sorting generated by a more efficient screening technology. It is argued that whereas more-able individuals will face higher probabilities of being hired (and, also, of experiencing direct job-to-job transitions), less-able workers will be confronted with lower arrival rates of job offers, thus lengthening their joblessness experience.

Suppose that job-offers arise as a Poisson process with rate $\lambda$, and that there are two types of workers, $A$ and $B$, with

$$
\lambda_{A}>\lambda_{B}
$$

The proportion of types $A$ (the more-able individuals) in the unemployment stock at $t$ is denoted by $p(t)$ and it is assumed, without loss of generality, that

\footnotetext{
${ }^{12}$ When one focuses only on those that have experienced a joblessness spell, we also see that duration has declined relative to unemployment rates in the left tail but increased in the right tail, further amplifying our previous result that short durations became shorter and longer durations became longer. It is not clear, however, whether this latter outcome can again be interpreted as a genuine shift in the unemployment duration distribution or simply an illusion produced by the (artificial) truncation of the distribution.
} 
$p(0)=1 / 2$. If all job offers are taken, the unemployment duration survivor function at $t$ is

$$
S(t)=p(t) \exp \left\{-\lambda_{A} t\right\}+(1-p(t)) \exp \left\{-\lambda_{B} t\right\}
$$

Better screening may be modelled by an increase in the exit rate from unemployment for the more able workers, $d \lambda_{A}>0$, and a decrease for the others, $d \lambda_{B}<0$. The impact of such a change is

$$
\frac{d S(t)}{S(t)}=-t\left[\theta(t) d \lambda_{A}+(1-\theta(t)) d \lambda_{B}\right]
$$

where

$$
\theta(t)=p(t) S_{A}(t) / S(t)
$$

Thus

$$
d S(t)>(<) 0 \text { iff } \omega(t) \equiv \frac{\theta(t)}{1-\theta(t)}<(>)-\frac{d \lambda_{B}}{d \lambda_{A}} .
$$

If the overall rate of job offers stays constant, $d \lambda_{A}+d \lambda_{B}=0$, it is therefore clear that $d S(t)>0$. That is, in this case one expects to observe the coexistence of both higher hazards at low durations together with longer average duration.

Alternatively, suppose there is an expansion of the exit rate from unemployment, that is $d \lambda_{A}+d \lambda_{B}>0$. Now, noticing that $\omega(0)=1$ and that $\omega^{\prime}(t)<0$, since $-d \lambda_{B} / d \lambda_{A}<1$ it is possible to find a $t^{\star}(>0)$ for which

$$
d S(t)<0 \text { for } t<t^{\star} \text { and } d S(t)>0 \text { for } t>t^{\star} .
$$

Consequently, better screening with expansion of job offers reduces duration on the left tail (makes short shorter) and increases durations in the right tail (makes long longer).

\section{Conclusions}

The starting point of this paper was the evidence that measured unemployment duration in the U.S. increased substantially relative to unemployment rates. In part, this was an illusion generated by the fact that job-to-job transitions are not included in the computation of average unemployment duration. But other mechanisms were at work increasing the hazard function for short-term unemployed and dampening the hazard function for long-term unemployed.

Here, the decomposition method proposed by Machado and Mata (2005) was employed in order to disentangle the contribution of the changes generated 
by covariates' distribution and the conditional distribution. The estimation indicates that compositional changes in the labor force played a limited role. Improved macroeconomic conditions visibly shifted the unemployment duration distribution to the left. But, apart from this mechanical impact, important structural changes, captured in the changes of the regression coefficients, were at play:

- Over the sampling period (1985-87 to 1995-97) there was a sharp increase in the incidence of direct job-to-job transitions that was above and beyond what would be expected from the decline in the unemployment rates.

- The conditional distribution of joblessness duration exhibited lower durations at low quantiles, implying that short durations became even shorter.

- On the right tail, however, the conditional distribution of joblessness duration, showed longer spells. In other words, long durations became even longer.

We rationalize our findings arguing that improved screening technology is likely to be the relevant underlying mechanism at work. It is argued that whereas more-able individuals will face higher probabilities of being hired (and also of experiencing direct job-to-job transitions), their less-able counterparts will confront a lower arrival rate of job offers, thereby lengthening their joblessness experience. A number of developments in the U.S. are likely to enhance the process of job screening: job search through the Internet, the increasing demand for placements through temporary help firms, and the use of profiling by the state unemployment insurance offices.

In a nutshell, if job screening is improved, thus enabling employers to better sort their job applicants, longer (measured) average unemployment duration may be an inevitable outcome of a more efficient labor market. In addition, if employers use the worker unemployment duration as a screening signal (Blanchard and Diamond, 1994), improved screening makes such a signal less blurred, further deepening the distinction between short- and long-term unemployed.

Finally, a note of caution is in order. These results rely solely on the joblessness experience of displaced workers and may not apply to other unemployment experiences, for example, the unemployment experience of job market incomers and re-entrants or job quitters. A longer time frame may also prove to be necessary in order to circumvent outcomes that may be cycle idiosyncratic. 


\section{References}

Abraham, Katherine and Robert Shimer (2001). Changes in unemployment duration and labor force attachment. NBER Working Paper No. 8513.

Addison, John T. And McKinley Blackburn (1994). The worker adjustment and retraining notification act. Journal of Economic Perspectives, 8, 181-190.

Addison, John T. and Pedro Portugal (1987). On the distributional shape of unemployment duration. Review of Economics and Statistics, 68, $520-526$.

Addison, John T. And Pedro Portugal (1992). Advance notice and unemployment: new evidence from the 1988 Displaced Worker Survey. Industrial and Labor Relations Review, 45, 645-664.

Autor, David (2001). Why do temporary help firms provide general skills training? Quarterly Journal of Economics, 116,4 1409-1448.

Autor, David, Lawrence Katz, and Melissa Kearney (2005). Trends in U.S. wage inequality: re-assessing the revisionists NBER working paper no. 1162\%.

Autor, David and David Scarborough (2004). Will job test harm minority workers? mimeo.

Bilias, Yannis, Songnian Chen, and Zhiliang Ying (2000). Simple resampling methods for censored regression quantiles. Journal of Econometrics, 99, 373-386.

Bassett, Gilbert And Roger Koenker (1986). Strong consistency of regression quantiles and related empirical processes. Econometric Theory, 2, 191-201.

Baumol, William and Edward Wolff (1998). Speed of technical progress and the length of the average interjob period. mimeo.

Berger, Mark, Dan Black and Jeffrey Smith (2001). Evaluating profiling as a means of allocating government services. in M. Lechner and F. Pfeiffer, eds. Econometric Evaluation of Labour Market Policies, ZEW and Physica-Verlag, Mannheim, Germany. 
Blanchard, Olivier and Peter Diamond (1990). The cyclical behavior of the gross flows of U.S. workers. Brookings Papers on Economic Activity, 2, 85-143.

Blanchard, Olivier and Peter Diamond (1994). Ranking, unemployment duration, and wages. Review of Economic Studies, 61, 417-434.

Buchinsky, Moshe (1994). Changes in the U.S. wage structure 19631987: application of quantile regression. Econometrica, 62, 405-458.

Cox, David And David Oakes (1984). Analysis of survival data. Chapman and Hall.

Fallick, Bruce and Charles Fleischman (2004). Employer-to employer flows in the U.S. labor market: the complete picture of gross worker flows. Federal Reserve Board, Finance and Economics Discussion Series Working Paper 2004-34.

Farber, Henry (2003). Mobility and stability: the dynamics of job change in labor markets. in O. Ashenfelter, G. S. Maddala, and D. Card, eds. Handbook of Labor Economics, vol. 3B, North-Holland.

Fitzenberger, Bernd (1997). A guide to censored quantile regression. in G. Maddala and C. Rao, eds. Handbook of Statistics, vol. 15, Elsevier Science B. V.

Hall, Robert (2005). Job loss, job finding, and unemployment in the U.S. economy over the past fifty years. Paper presented at NBER Macro Annual Conference, April 2005.

Houseman, Susan (2001). Why employers use flexible staffing arrangements: evidence from an establishment survey. Industrial and Labor Relations Review, 55, 149-170.

Juhn, Chinhui, Kevin Murphy, And Robert Topel (2002). Current unemployment, historically contemplated. Brookings Papers of Economic Activity, 1, 79-116.

Katz, Lawrence and Alan Krueger (1999). The high-pressure U.S. labor market of the 1990s, Brookings Papers of Economic Activity, 1, 1-87.

Koenker, Roger (1991). Quantreg: A quantile regression package for R. http://cran.r project.org. 
Koenker, Roger and Gilbert Bassett Jr. (1978). Regression Quantiles. Econometrica, 46, 33-50.

Koenker, Roger and Stephen Portnoy (1997). The Gaussian hare and the Laplacian tortoise: computability of squared-error versus absoluteerror estimators. Statist, Sci., 12, 279-300.

Kuhn, Peter and Mikal Skuterud (2004). Internet job search and unemployment duration. American Economic Review, 94,1 218-232.

Machado, José and JosÉ Mata (2005). Counterfactual decomposition of changes in wage distributions using quantile regression. Journal of Applied Econometrics, 20, 445-465.

Manski, Charles (1988). Analog estimation methods in econometrics. Chapman and Hall.

Mukoyama, Toshihiko and Aysegül Sahin (2004). Why did average duration of unemployment become so much longer? mimeo.

Powell, James (1984). Least absolute deviations for the censored regression model. Journal of Econometrics, 25, 303-325.

Powell, James (1986). Censored regression quantiles. Journal of Econometrics, 32, 143-155.

Silverman, B. W. (1986). Density Estimation for Statistics and Data Analysis. Chapman and Hall.

Shimer, Robert (2005). The cyclicality of hires, separations, and jobto-job transitions. mimeo.

Valletta, Robert (1998). Changes in the Structure and Duration of U.S. Unemployment, 1967-1998. Federal Reserve Bank of San Francisco Economic Review, 3, 29-40. 


\section{Appendix A: Econometric methodology}

\section{Censored quantile regressions}

Let $T_{i}$ represents the duration of the "most representative" unemployment spell of individual $i$ and $x_{i}\left(x_{1 i} \equiv 1\right)$ be the vector of covariates for the $i$ th observation. We consider statistical models specifying, the $p$ th $(p \in(0,1))$ quantile of $T$ as

$$
Q_{y(T)}(p \mid x)=x^{\prime} \beta(p)
$$

where $y(\cdot) \equiv \log$ and $\beta(p)$ is a vector of QR parameters, varying from quantile to quantile.

Our sample provides information on complete unemployment durations, but there are some incomplete spells (right-censoring). Moreover, to avoid problems with taking logs of very short spells ( 0 or close to 0 weeks) we, arbitrarily, censored durations inferior to 0.25 at 0.25 weeks. The sample information we consider may thus be represented by $\left(y_{i}^{\star}, x_{i}\right), i=1, \ldots, n$ where $y_{i}^{\star}=\min \left[\max \left(y_{i}, l\right), u_{i}\right], u_{i}$ denotes the upper threshold for $y_{i}$ and $l$ the leftcensoring point $(l=\log (0.25))$. When observation $i$ is not censored $u_{i}$ was taken to be the potential censoring duration (for instance, for a spell of six weeks starting in March 1997, $u_{i}$ was 44 weeks). The QR estimator minimizes the sample objective function

$$
\sum_{i=1}^{n} \rho_{p}\left(y_{i}-\min \left[u_{i}, \max \left(x_{i}^{\prime} b, l\right)\right]\right)
$$

with,

$$
\rho_{p}(z)=\left\{\begin{array}{cc}
p z & \text { for } z \geq 0 \\
(p-1) z & \text { for } z<0
\end{array}\right.
$$

(Powell 1984, 1986). Estimation was performed iteratively using Buchinsky's (1994) ILPA procedure with the modification suggested by Fitzenberger (1997). The quantile estimation uses the Frisch-Newton algorithm (see Koenker and Portnoy, 1997) implemented in the function rq in the quantreg package for $\mathrm{R}$, Koenker (1991). For the estimation of standard errors for the individual coefficients we resort to the bootstrap. Since the "errors" from the QR equation are not necessarily homogeneously distributed, to achieve robustness we resample $(y, x, l, u)$ following the method of Billias et al. (2000).

Due to censoring, it may not be possible to identify the whole quantile process. Let $\left(p_{l}, p_{u}\right)$ represent the range of quantiles that can be consistently estimated. Technically, any $p$ in that range must be such that 


$$
M_{n}(p)=E\left\{\frac{1}{n} \sum_{i=1}^{n} I\left(l+\xi<x_{i}^{\prime} \beta(p)<u_{i}-\xi\right) x_{i} x_{i}^{\prime}\right\}
$$

is uniformly positive definite in $n$ for some $\xi>0$ (Fitzenberger (1997), Theorem 2.1).

\section{Machado and Mata decomposition}

The conditional quantile process - i.e., $Q_{y}(p \mid x)$ as a function of $p \in(0,1)$ - provides a full characterization of the conditional unemployment duration in much the same way as ordinary sample quantiles characterize a marginal distribution. The resampling procedures proposed in Machado and Mata (2005) (henceforth, M\&M) provide an easy way of simulating a random sample, $\left\{T_{i}^{\star}, i=1, \ldots, m\right\}$, from a conditional distribution of duration times that is consistent with the restrictions imposed on the conditional quantiles by the QR model. For completeness we outline here the procedure:

1. Generate $m$ random draws from a Uniform distribution on $\left(p_{l}, p_{u}\right), \pi_{i}, i=$ $1, \ldots, m$

2. For each $\pi_{i}$ estimate the QR model (1), thereby obtaining $m$ vectors $\hat{\beta}\left(\pi_{i}\right)$;

3. For a given value of the covariates, $x_{0}$,

$$
T_{i}^{\star} \equiv \hat{Q}_{T}\left(\pi_{i} \mid x_{0}\right)=g\left(x_{0}^{\prime} \hat{\beta}\left(\pi_{i}\right)\right) i=1, \ldots, m,
$$

is a random sample from the estimated conditional c.d.f. $F_{T}\left(t \mid X=x_{0}\right)$ censored at $p_{l}$ and $p_{u}$.

The sample generated by the procedure above is drawn from the conditional distribution. In many instances it is important to integrate out the conditioning covariates. This integration or marginalization can be performed with respect to different joint distributions, $g(x)$, of the covariates. The approach in M\&M may be described as follows:

1. As described before, generate $\pi_{i}, i=1, \ldots, m$ and estimate the corresponding $\hat{\beta}\left(\pi_{i}\right)$;

2. Generate a random sample of size $m$ from a given $g(x)$; let it be denoted by $\left\{x_{i}^{\star}\right\}, i=1, \ldots m$. 
3. Obtain

$$
T_{i}^{\star} \equiv \hat{Q}_{T}\left(\pi_{i} \mid x_{i}^{\star}\right)=g\left(x_{i}^{\star^{\prime}} \hat{\beta}\left(\pi_{i}\right)\right)
$$

which is a random sample from the marginal distributions of durations times implied by the model postulated for the quantile process and by the assumed joint distribution of the covariates.

When $g(x)$ is an estimate of the actual distribution of the covariates in the population, the resulting sample of durations is drawn from the actual marginal distribution. In this case, $\left\{x_{i}^{\star}\right\}$ may be obtained by drawing with replacement from the rows of $\mathcal{X}$, the regressors' data matrix. But, in reality, $g(x)$ may be any distribution of interest. If it is an estimate of the distribution of the covariates in $1988(g(x(1988)))$, the resulting durations will constitute a simulated sample from the marginal distribution of durations that would have prevailed in 1998 if all covariates had been distributed as in 1988, (assuming, of course, that the $\beta$ vector was estimated with 1998 data).

Comparing this counterfactual sample with samples of durations from the actual marginals for 1998 and 1988, it is possible to derive Oaxaca type decompositions for the entire distribution, rather than for just its mean. Specifically, it is possible to decompose the observed changes in those due to changes in the conditional distribution of durations (the $\beta$ 's) and those stemming from changes in the joint distribution of the covariates. Other decompositions of interest often involve isolating the contribution of a single covariate. For further details on how to implement this decomposition, see M\&M.)

In the implementation of the method in this paper we made $p_{l}=0.10$ and $p_{u}=0.95$ and estimated the quantile regression coefficients at equally spaced intervals of length 0.005 . We then draw $1000(=m)$ of such estimates with replacement. A code in $\mathrm{R}$ with the whole procedure is available on request.

\section{Hazard functions estimation}

Having obtained a simulated random sample, $\left\{T_{i}^{\star}, i=1, \ldots, m\right\}$, from the distribution of duration time of interest (conditional, marginal or counterfactual) the usual methods of density estimation and hazard function estimation may be applied. In situations where, due to censoring, the top quantiles cannot be consistently estimated, the estimated function must be adequately rescaled. Specifically, assuming that quantile process is only identified in $\left(p_{l}, p_{u}\right)$, the 
results in Silverman (186, p.148) yield,

$$
\hat{h}(t \mid x)=\frac{\left(p_{u}-p_{l}\right) f^{\star}(t)}{1-p_{l}-\left(p_{u}-p_{l}\right) F^{\star}(t)}
$$

where $f^{\star}(t)$ is the usual kernel density smoother of $T_{i}^{\star}$,

$$
f^{\star}(t)=\frac{1}{m h} \sum_{i=1}^{m} K\left(\frac{t-T_{i}^{\star}}{h}\right)
$$

and the distribution function estimator is,

$$
F^{\star}(t)=\frac{1}{m} \sum_{i=1}^{m} \mathcal{K}\left(\frac{t-T_{i}^{\star}}{h}\right)
$$

with

$$
\mathcal{K}(u)=\int_{0}^{u} K(v) d v
$$

